\title{
Dynamics of investor communication in equity crowdfunding
}

\author{
Gregor Dorfleitner $^{1} \cdot$ Lars Hornuf $^{2,3,4} \cdot$ Martina Weber $^{1}$
}

Received: 23 November 2017 / Accepted: 16 April 2018 / Published online: 17 May 2018

(C) The Author(s) 2018

\begin{abstract}
In crowdfunding, start-ups can voluntarily communicate with their investors by posting updates. We investigate whether start-ups strategically use updates, which have previously been shown to increase investments. To this end, we use hand-collected data from 751 updates and 39,036 investment decisions from two major German equity crowdfunding portals: Seedmatch and Companisto. We find evidence of strategic communication behavior of start-ups during an equity crowdfunding campaign. During the funding period, start-ups more frequently post updates with linguistic devices that enhance the group identity and the group cohesion as well as updates on the business development. Furthermore, the probability of an update during the funding period increases along with strong competition of other contemporary crowdfunding campaigns.
\end{abstract}

Keywords Crowdfunding · Investor communication · Entrepreneurial finance · Sentiment analysis · Linguistic devices

JEL Classification G21 · G24 · G32 - L11 · L26

\section{Introduction}

In recent years, equity crowdfunding has gained increasing importance in providing start-ups with funding. In contrast to traditional early-stage financing sources such as venture capital and banks, equity crowdfunding has introduced the possibility for non-sophisticated private investors to invest in start-ups. However, there are crucial differences between the information rights and the experience of

Responsible Editor: Ioanna Constantiou

Lars Hornuf

hornuf@uni-bremen.de; lars.hornuf@ip.mpg.de

Gregor Dorfleitner

Gregor.Dorfleitner@ur.de

Martina Weber

Martina.Weber@ur.de

1 Department of Finance, University of Regensburg, Universitätsstr. 31, 93053, Regensburg, Germany

2 University of Bremen, Faculty of Business Studies and Economics, Wilhelm Herbst Straße 5, 28359 Bremen, Germany

3 Max Planck Institute for Innovation and Competition, Marstallplatz 1, 80539 München, Germany

4 CESifo, Poschingerstr. 5, 81679 München, Germany venture capitalists and crowd investors. In this article, we therefore analyze the communication behavior of startups in equity crowdfunding during and after the funding period and investigate whether entrepreneurs use voluntary disclosure strategically.

Recent academic research in equity crowdfunding analyzes follow-up fundings, crowd exits and insolvencies of successfully funded equity crowdfunding campaigns (Hornuf and Schmitt 2016; Signori and Vismara 2018; Hornuf et al. 2018). However, the majority of the literature investigates determinants of the funding success of a campaign. A correlation between the success of campaigns and the size and education of the management team as well as particular project characteristics-e.g. the share of equity offered or disclosure of financial projections-has been shown (Ahlers et al. 2015; Vismara 2016; Bernstein et al. 2017). Furthermore, the posting of voluntary information in the form of updates during the campaign increases the likelihood of funding success (Mollick 2014; Block et al. 2018).

Both the crowdfunding and the corporate finance literature (Diamond and Verrecchia 1991; Healy and Palepu 2001; Merton 1987) provide evidence of a positive impact of voluntary disclosure on the funding success or the company value, respectively. Yet Block et al. (2018) find that the effect of updates on the success of equity crowdfunding 
campaigns depends on the content of the published information. Not all updates have a positive impact on the invested amount and the number of investments. Updates with verifiable and business-related information about the development of the start-up are most relevant, while the business model, team, and promotional activities evoke less interest among investors. Furthermore, the language of updates, i.e. the sentiment, can influence the perception of the investors. In our paper we reverse the research question of Block et al. (2018). Instead of investigating the effect of updates on the funding success, we examine whether startups take into account these previously shown relationships and strategically post updates containing a specific language or content. To this end, we investigate the sentiment, the language, and the content of updates. First, we analyze changes in the communication behavior during and after the funding period. Second, we focus solely on the funding period and investigate which circumstances increase the likelihood of start-ups posting an update.

We use hand-collected data from two major German equity crowdfunding portals-Seedmatch and Companisto- to investigate the communication behavior of start-ups. Therefore, we use the data set of Block et al. (2018) and expand it with further updates posted during $^{1}$ and after the funding period. Through analyzing the language and the content of 751 updates as well as 39,036 individual investment decisions, we find evidence that start-ups use updates during the funding period strategically. The frequency of updates is significantly higher over the course of the funding period than afterwards and start-ups use more linguistic devices that create a feeling of group cohesion and group identity. We also find some evidence for the hypothesis that start-ups strategically post updates with specific content during the funding period. Moreover, during the funding period the probability of an update increases along with strong competition of other contemporary equity crowdfunding campaigns.

Our study thus contributes to answering the question of whether start-ups rationally use investor communication to ensure successful funding and to what extent and in what way they change their communication behavior after the funding is ensured. While the answer to the first question could help to improve the entrepreneurial behavior in crowdfunding campaigns, the latter aspect may be important for both the decision making of investors and in the context of investor protection. Knowledge about the possibly strategic communication behavior of start-ups can help investors to optimize their investment decisions. All these

\footnotetext{
${ }^{1}$ On Seedmatch, entrepreneurs can post updates on two different parts of the webpage. In contrast to Block et al. (2018) we take into account both of these possibilities to publish updates. In this way, we make use of additional 80 updates during the funding period.
}

issues are highly relevant for the continued development of the regulatory framework for equity crowdfunding.

The remainder of the paper is structured as follows. In "Theoretical foundation and hypotheses" we describe our hypotheses regarding changes in the communication behavior of start-ups and the determinants of updates during the funding period. Section "Data" provides an overview of the data set and the key variables. Section "Results" presents descriptive statistics and analyzes the use of updates in equity crowdfunding. Section "Conclusion" concludes.

\section{Theoretical foundation and hypotheses}

In crowdfunding, updates are a form of voluntary disclosure for start-ups. There are several reasons why start-ups publish updates both during and after the funding period of the campaign, thereby informing (potential) investors about developments regarding the start-up.

Generally, the managers of a company are assumed to have comparatively good knowledge of the firm value and the expected future performance of the company than investors. These information asymmetries between managers and shareholders can be reduced by providing additional information through voluntary disclosure. Furthermore, updates can serve as a signal of quality (Mollick 2014; Block et al. 2018). According to Spence (2002), signals can further reduce information asymmetries between the involved parties. Lower information asymmetries, can in turn, reduce the cost of capital for companies (Diamond and Verrecchia 1991; Healy and Palepu 2001; Merton 1987). Rational entrepreneurs can therefore be expected to publish updates during the funding period of a campaign. Previous research shows that updates are indeed important for the funding success of a crowdfunding campaign (Xu et al. 2014; Mollick 2014; Kuppuswamy and Bayus 2017; Block et al. 2018; Hornuf and Schwienbacher 2017).

Subsequent to the funding period, communication with investors is rational as well. The reasons for participation in crowdfunding are diverse. Hamari et al. (2016) describe internal motivations such as perceived sustainability and enjoyment as well as external motivations including reputation and economic benefits. Therefore, monetary motives may not necessarily be the only reason either for entrepreneurs or for investors to engage in equity crowdfunding. Particularly in crowdfunding, the support and feedback of the crowd both in the development and promotion of products and services can be considered as being important for the future success of the startup. If these non-monetary incentives play a role for investors and the start-up, we expect the entrepreneur to communicate with the investors both during and after the campaign. 
In crowdfunding, no regulations concerning the form or the content of voluntary disclosure exist, and usually no third party verifies the published information. Therefore, entrepreneurs can easily make use of the signaling effect of updates and strategically post updates with specific content or language during the funding period. In this way, they can signal quality to investors and thereby gain investments. As the business development of the start-up is not different at any specific time during or directly after the funding period ends per se, the availability of the disclosable hard information should not significantly change during and after the funding period. Hence, if either the language or the content of updates significantly differs between these two periods, we conclude that start-ups strategically post updates to encourage investors. In the following, we derive several hypotheses regarding such strategic communication behavior of start-ups.

The financial disclosure literature indicates that an optimistic and positive tone of reports is associated with increased firm performance (Li 2010; Davis et al. 2012; Henry 2008). For example, Henry (2008) investigates the effect of language used in earnings press releases on the stock price. He shows that press releases written in a positive tone are associated with higher abnormal returns. The results remain stable even after controlling for the financial results of the company. Positivity is also closely linked to the concept of passion in the literature on entrepreneurship. Empirical evidence suggests that the optimism, passion, and self-confidence of an entrepreneur increase the likelihood of obtaining venture capital and indirectly raise the prospects of future growth (Baum and Locke 2004; Cardon et al. 2009; Chen et al. 2009). Start-ups might prefer to use updates with a more positive tone during the funding period to show that they are passionate and optimistic. As the business development of start-ups should not be better in the funding period than afterwards per se, a more positive tone during the funding period suggests strategic communication behavior of start-ups.

Hypothesis 1: During the funding period, updates have a more positive tone than after the funding period.

Furthermore, Allison et al. (2013) use the warmglow theory of Andreoni (1990) to explain funding success on Kiva, a crowdfunding platform for micro loans. The warm-glow theory suggests that individuals receive utility by helping others. By examining the credit applications of micro loans, Allison et al. (2013) show that credit applications containing linguistic devices that evoke warm-glow effects experience faster funding. Gerber and Hui (2013) find similar motives for other forms of crowdfunding. They point out that investors are motivated by the desire to help others and to be part of a community. By publishing updates with specific linguistic devices that evoke a feeling of cohesion start-ups may try to use this coherence. Using emotional language and the first person plural can create a feeling of group identity and improve the group cohesion (Zheng 2000; Sexton and Helmreich 2000; Tausczik and Pennebaker 2010). Furthermore, using the past tense can create a psychological distance (Tausczik and Pennebaker 2010) and therefore, we expect start-ups to strategically employ the first person plural, more frequently use emotional language, and increase the use of the present tense in updates during the funding period. Such communication behavior of start-ups tends to indicate a strategic use of language in updates since, on average, the disclosable hard information should not significantly change during and after the funding period.

Hypothesis 2: During the funding period, updates contain more linguistic devices that evoke a feeling of group cohesion than they do after the funding period.

As there are no rules concerning the content of updates in crowdfunding, start-ups can generally publish any type of information in updates. Yet it is not surprising that not all forms of updates promote the funding success of a campaign (Xu et al. 2014; Block et al. 2018). In particular, updates informing about new developments of start-ups such as new funding sources, the development of the respective business, and updates containing information about cooperations increase the funding success within the funding period. By contrast, updates with information that was previously available such as information about the entrepreneurial team or the business model are not significantly associated with an increase in investments (Block et al. 2018). If entrepreneurs wish to target the investment spirit, start-ups can be expected to publish disproportionately more updates disclosing information about new developments during the funding period than after the funding period. Again, as there should not per se be a higher density of these new developments within the funding period than later on, posting relatively fewer of these updates after the end of the campaign provides evidence of strategic communication behavior of start-ups.

Hypothesis 3: During the funding period, entrepreneurs publish more updates with information on new funding sources, the business development, and updates with information about cooperations of the start-up.

On most of the equity crowdfunding platforms, startups define a funding goal before the campaign begins. The funding goal represents the threshold of the invested amount of money the start-ups need to obtain to be successfully funded. Therefore, start-ups have a strong incentive to obtain investments worth a minimum of the amount of the 
funding goal. Hornuf and Schwienbacher (2017) highlight the L-shape of investments under a first-come-first-served mechanism in equity crowdfunding. Vulkan et al. (2016) find that the chances for successful funding decrease after the campaign has begun. Hence, start-ups that are almost at the end of the funding period and have attracted investments below the funding goal are expected to act promptly in order to gain more backers. They may post more updates to trigger the investments needed to reach the funding goal, even if the probability of disclosable information does not change over the course of the funding period.

Hypothesis 4: Start-ups are more likely to post an update when the funding goal of the campaign has not been achieved and the remaining funding period is short.

During the funding period, start-ups may also consider the competitive environment of their equity crowdfunding campaigns. Many parallel equity crowdfunding campaigns or so-called blockbusters, popular campaigns with an extremely large number of backers, may lure investors away from the focal crowdfunding campaign. When competition is strong, start-ups may be more likely to post an update to draw attention to their own campaign. However, previous research indicates that blockbusters not only accelerate investments in the focal campaign but also increase them in other crowdfunding campaigns (Kickstarter 2012). This is because blockbusters usually enjoy extensive media coverage and new backers may be attracted to crowdfunding in general. With data from the reward-based crowdfunding portals Kickstarter and Indiegogo, Doshi (2016) shows that, on average, the invested volume increases in the blockbusters' project category. Depending on the project category, blockbuster can also create spill-over effects to other project categories. Darrough and Stoughton (1990) analyze voluntary disclosure in competitive markets. They highlight that under some assumptions such as low entry costs to the market, strong competition favors voluntary disclosure to deter the entry of competitors. In the context of equity crowdfunding, Hornuf and Schwienbacher (2017) and Block et al. (2018) find a positive relationship between a strong competition of campaigns and the funding success of a particular campaign. Overall, the probability of disclosing voluntary information in the form of updates can be expected to increase in a highly competitive environment. Since the available disclosable hard information should not depend on the competitive environment, such communication would again suggest a strategic behavior of start-ups.

Hypothesis 5: Start-ups are more likely to post an update when the number of competing investments in contemporary equity crowdfunding campaigns is high.

\section{Data}

\section{Data sources}

For the empirical analysis we hand-collect data from two German equity crowdfunding portals-Seedmatch and Companisto-during the period from June 72012 to April 27 2015. The portals Seedmatch and Companisto are the market leaders for equity crowdfunding in Germany and account for around $75 \%$ of the total equity crowdfunding capital raised in Germany during the observation period. We obtain all data directly from the platforms. Habitually, startups do not only use equity crowdfunding portals to post their updates but also publish the information on social media platforms or in newsletters. After the campaign, the equity crowdfunding portals retain a page with a project overview as well as all key characteristics of the campaign and the possibility to post updates. As start-ups also seek visibility when the campaign has concluded, we expect the start-ups still to use all communication channels including the equity crowdfunding portals, in order to post their updates. For the further analysis we use two different data sets.

To analyze changes in the communication behavior of start-ups we focus on the updates posted during and after the funding period and examine all campaigns run on Seedmatch and Companisto that include at least one update. In total, our first data set (updates data set) includes 751 updates of 97 equity crowdfunding campaigns. With 64 campaigns the majority of the 97 campaigns were run on Seedmatch. Yet start-ups running equity crowdfunding campaigns on Companisto appear to post more updates. Approximately $52 \%$ of the updates in our data set were posted on this portal. Several start-ups run multiple equity crowdfunding campaigns, hence the 97 campaigns belong to 88 unique start-ups. Most of these start-ups operate either in the information \& communication or in the wholesale \& retail sectors.

We additionally obtained a second data set with daily investment data for 71 campaigns (investment data set) to further investigate the determinants of updates during the funding period. Investment data refers to the daily investments of all backers as well as the total invested amount on each campaign day. We were able to retrieve investment data for 26,456 investments belonging to the entire 36 campaigns on Companisto. We also retrieved daily investment data for 12,580 investments and 35 campaigns on Seedmatch. Seedmatch removes all investment data from the website once the funding has been completed and hence the amounts invested by individual backers are no longer publicly available. Due to this limited availability of data we could not include all campaigns run on Seedmatch in the investment data set. Importantly, during the funding period only 57 campaigns include updates, which were 
also considered in the updates data set. We also obtain investor data for 14 campaigns that refrained from posting any updates during the funding period. Overall, eight startups ran multiple equity crowdfunding campaigns; thus the 71 campaigns belong to 63 unique start-ups. In a final step, as in Kuppuswamy and Bayus (2017) and Hornuf and Schwienbacher (2017), we construct a panel data set in which the time dimension is equal to the days of the campaign and the cross-sectional dimension is represented by the campaigns. The investment data set contains 5,176 campaign days and 314 updates posted on these days.

\section{Dependent variables and key explanatory variables}

To test our hypotheses, we define different dependent variables. For each day of the funding period, we identify whether the start-up posted an update or not (Update). Furthermore, we consider all updates posted during and after the funding period and examine the content and the language of these updates. We apply a coding process to examine the information contained in the updates. Following Block et al. (2018), we use nine categories to describe the content of the updates: Team, BusinessModel, Certification, Product, Cooperation, Campaign, NewFunding, Business, and Promotions. A detailed description of all the categories is included in Table 1. The categories are not mutually exclusive; different categories can apply to one update. Furthermore, updates without relevant content are not included in any of the categories.

To ensure the reliability of our coding scheme, a second, independent researcher rated the updates. At first, we provide the second researcher with a coding manual containing a detailed description of each category. The researcher rated approximately $20 \%$ of the updates. In a following discussion, we adapt our coding scheme and come up with the final description of the ten categories. Thereafter, both raters coded all updates again (Reis and Judd 2014). To measure the inter-rater agreement, we calculate the Cohen's Kappa coefficient (Cohen 1960; Fleiss et al. 2003). Over all categories we have a Cohen's Kappa of 0.85 . Depending on the category, the inter-rater reliability ranges from 0.77 to 0.94 indicating excellent agreement $^{2}$ between the two raters (Landis and Koch 1977).

To further evaluate the sentiment and the language of the updates, we use the text analysis software Linguistic Inquiry and Word Count (LIWC) (Pennebaker et al. 2001; Wolf et al. 2008). LIWC counts the words in the updates and compares them with dictionaries of different linguistic and psychological categories (for example positive or negative emotions). The software calculates the percentage of total words for each category. Thus we can measure the sentiment

\footnotetext{
${ }^{2}$ According to Landis and Koch (1977) a Cohen's Kappa between 0.61 and 0.8 indicate substantial agreement, values above 0.81 indicate almost perfect agreement.
}

of the updates (Positive and Negative) and the usage of the past tense (Past) as well as the usage of first person plural $(W e)$. In general, the start-ups have 60 days to gain enough investments to reach their funding goals (funding period) subsequent to the publication of the campaign on the crowdfunding platform. However, for each campaign the start-ups can extend the funding period one time only for another 60 days (Klöhn and Hornuf 2012). To investigate changes in the communication behavior, we derive the variable $F I N$.

By using daily investment data, we define several key explanatory variables. We measure the success of a campaign using two different proxies. On the one hand, we create the dummy Alarm. Alarm accounts for the startups that urgently require further investments, in the sense that the hitherto invested amount has not yet reached the funding goal and the remaining time of the funding period is short. On the other hand, we use the variable Amount. Moreover, we measure the competitive environment of a campaign (\#Investments).

We also include several further control variables based on prior research. Hornuf and Schwienbacher (2017) show that investments in equity crowdfunding decrease under a first-come-first-served mechanism once the funding goal has been surpassed. Therefore, we include a dummy variable PostFunded. In another paper, Hornuf and Neuenkirch (2017) demonstrate that a high level of stock market volatility is associated with higher premia for the equity crowdfunding portal Innovestment. The authors conclude that equity crowdfunding is a substitutional, as opposed to a supplementary asset class, when stock markets are volatile. Thus we also include the German VDax $(V D A X)$ as a control variable. To capture portalspecific effects, we include a dummy variable for the equity crowdfunding portal Companisto (Portal). Finally, we control for the industry of the start-up, the year, and the day of the week (see, for example, Vismara 2016, Block et al. 2018, Hornuf and Neuekirch 2017). A description of all variables is presented in Table 1.

\section{Results}

\section{Summary Statistics}

Table 2 presents summary statistics for the updates data set. The majority of the 751 updates is published during the funding period. However, we also consider 299 updates that are subsequently posted. ${ }^{3}$ The bulk of the updates discloses

\footnotetext{
${ }^{3}$ In our data set, the average funding period is with 72 days considerably shorter than the average period following successful funding (573 days).
} 
Table 1 List and definition of all variables

\begin{tabular}{|c|c|}
\hline Variable & Description \\
\hline \multicolumn{2}{|c|}{ Updates and Update Categories } \\
\hline Update & Dummy variable equal to 1 if the start-up publishes an update on day $t$, and 0 otherwise. \\
\hline Business & $\begin{array}{l}\text { Dummy variable equal to } 1 \text { if the update on day } t \text { discloses information about the customers or } \\
\text { financials (e.g. number of customers, amount of sales), and } 0 \text { otherwise. }\end{array}$ \\
\hline Business Model & $\begin{array}{l}\text { Dummy variable equal to } 1 \text { if the update on day } t \text { discloses information about the business model, } \\
\text { the relevant market or future plans and strategies, and } 0 \text { otherwise. }\end{array}$ \\
\hline Campaign & $\begin{array}{l}\text { Dummy variable equal to } 1 \text { if the update on day } t \text { discloses information on the funding of the } \\
\text { campaign (e.g. number of investors, archived funding amount, change of funding limit), and } 0 \\
\text { otherwise. }\end{array}$ \\
\hline Certification & $\begin{array}{l}\text { Dummy variable equal to } 1 \text { if the update on day } t \text { discloses information on external certification of } \\
\text { the company or product (e.g. press coverings, awards, patents), and } 0 \text { otherwise. }\end{array}$ \\
\hline Cooperation & $\begin{array}{l}\text { Dummy variable equal to } 1 \text { if the update on day } t \text { discloses information on cooperation projects or } \\
\text { collaborations of the start-up, and } 0 \text { otherwise. }\end{array}$ \\
\hline Emotional & Dummy variable equal to 1 if the update on day $t$ contains emotional language, and 0 otherwise. \\
\hline New Funding & $\begin{array}{l}\text { Dummy variable equal to } 1 \text { if the update on day } t \text { discloses information on additional funding sources } \\
\text { of the start-up such as business angels, venture capitals or government grants, and } 0 \text { otherwise. }\end{array}$ \\
\hline Product & $\begin{array}{l}\text { Dummy variable equal to } 1 \text { if the update on day } t \text { discloses information on the product or the product } \\
\text { development, and } 0 \text { otherwise. }\end{array}$ \\
\hline Promotions & $\begin{array}{l}\text { Dummy variable equal to } 1 \text { if the update on day } t \text { discloses information about promotions for the } \\
\text { crowd (discounts, rewards), invites the crowd to participate on events or appeals to the crowd to } \\
\text { support the start-up (e.g. recommendations and network), and } 0 \text { otherwise. }\end{array}$ \\
\hline Team & $\begin{array}{l}\text { Dummy variable equal to } 1 \text { if the update on day } t \text { discloses information about the entrepreneurial } \\
\text { team (e.g. work experience, age and education), and } 0 \text { otherwise. }\end{array}$ \\
\hline
\end{tabular}

Sentiment and Language of Updates Negative

Past

Positive

$W C$

We
Percentage of words that evoke negative emotions within the update text (e.g. hurt, ugly and nasty). Obtained by the software LIWC.

Percentage of words that refer to the past within update text (e.g. went, had and ran). Obtained by the software LIWC.

Percentage of words that evoke positive emotions within the update text (e.g. love, nice and sweet). Obtained by the software LIWC.

The total number of words that appear in the update text.

Percentage of words that refer to first person plural within the update text (e.g. we, us and our). Obtained by the software LIWC.

\section{Timing of Updates and Competitive Environment}

Alarm

FIN

Interval

\# Investments

Time

Update 1 Day

Controls

Amount

Funding Goal

Equity Share

Industry
Dummy variable equal to 1 if the funding goal is not reached and more than three quarters of the funding period have passed or three quarters of the extended funding period, and 0 otherwise.

Dummy variable equal to 1 if the update is published during the funding period, and 0 otherwise. Time interval between the publications of updates in a particular campaign, in days.

Total number of all investments made on day $t$ across all campaigns on three major and one minor German equity crowdfunding portal (Companisto, Seedmatch, Innovestment, and United Equity).

Total number of days passed from the start of the campaign before publishing the first update. Updates on the first campaign day are either considered (subsample 2) or not (subsample 1).

Dummy variable equal to 1 if an update is published on the first day of the campaign, and 0 otherwise.

Total amount of money invested by the crowd until day $t$ in a particular campaign, in Euro. The minimum funding goal as defined by the start-up and the portal on day 0, in Euro. Funding Goal over pre-money valuation.

Dummy variables for the industry in which the start-up operates in, either information \& communication; wholesale \& retail; manufacturing; professional, scientific \& technical activities; financial $\&$ insurance activities or accommodation $\&$ food service activities. 
Table 1 (continued)

$\begin{array}{ll}\text { \% Invested } & \text { Amount over funding goal at day } t \text { in a particular campaign. } \\ \text { Post Funded } & \text { Dummy variable equal to } 1 \text { if the invested sum of money of the campaign has exceeded the funding } \\ \text { goal on day } t \text { in a particular campaign, and } 0 \text { otherwise. }\end{array}$

The data is retrieved from the German equity crowdfunding portals Seedmatch and Companisto

information on promotions of the start-ups and / or describes the business model. By contrast, only few updates contain emotional language and disclose information either about the entrepreneurial team or new funding sources. Some start-ups use updates extensively to communicate with their investors. In total, the start-up Riboxx posted 29 updates since its campaign start in July 2014. On average, 33 days pass before a subsequent update is posted in a particular campaign. However, the length of this interval differs between the two portals. On Companisto an average of 28 days pass between the posting of an update. On Seedmatch though, this interval is, on average, 39 days. The length of the updates varies considerably as well. The shortest update only consists of one word ("Danke", meaning thanks) while the longest contains 1,293 words. Furthermore, the updates employ a relatively positive tone. Approximately $3.9 \%$ of the words are positive and, by contrast, only around $0.3 \%$ are negative.
Summary statistics for the investment data set are shown in Table 3. More than $80 \%$ of the campaigns have at least one update during the funding period. On average, a startup posts 4 updates during this time. However, the number of updates differs between the campaigns. Some start-ups refrain from posting a single update while others use this tool for communication extensively. For example, the startup MyParfume posted 14 updates during the funding period. Yet, the campaign length of MyParfume is above the average of 72 days (123 days). As soon as the campaign becomes active and backers have the possibility to invest, start-ups are able to communicate with their investors via updates. Most of the start-ups post their first update at the beginning of the funding period (see Fig. 1). Several start-ups even post updates on the very first day of the campaign. These updates are rarely linked to the progress of the campaign. As described in Mollick (2014), start-ups may strategically

Table 2 Summary statistics updates data set

\begin{tabular}{|c|c|c|c|c|c|c|c|}
\hline \multicolumn{8}{|c|}{ UPDATES DATA SET } \\
\hline Binary Variables & Yes & Mean & Median & SD & \# Obs. & Corr & \\
\hline FIN & 452 & 0.602 & 1 & 0.4898 & 751 & & \\
\hline Business & 184 & 0.245 & 0 & 0.4303 & 751 & 0.1597 & \\
\hline Business Model & 345 & 0.155 & 0 & 0.3629 & 751 & 0.0292 & \\
\hline Campaign & 143 & 0.190 & 0 & 0.3928 & 751 & 0.2420 & \\
\hline Certification & 283 & 0.376 & 0 & 0.4849 & 751 & -0.1141 & \\
\hline Cooperation & 170 & 0.226 & 0 & 0.4187 & 751 & 0.0174 & \\
\hline Emotional & 117 & 0.156 & 0 & 0.3629 & 751 & 0.1019 & \\
\hline New Funding & 51 & 0.067 & 0 & 0.2517 & 751 & 0.0574 & \\
\hline Product & 292 & 0.388 & 0 & 0.4878 & 751 & 0.4878 & \\
\hline Promotions & 347 & 0.462 & 0 & 0.4988 & 751 & -0.1247 & \\
\hline Team & 87 & 0.116 & 0 & 0.3203 & 751 & -0.0201 & \\
\hline Metric Variables & Mean & Median & SD & Min. & Max. & \# Obs. & Corr \\
\hline Positive (in \%) & 3.981 & 3.54 & 4.0948 & 0.00 & 100.00 & 751 & 0.0094 \\
\hline Negative (in \%) & 0.262 & 0 & 0.4700 & 0.00 & 4.26 & 751 & -0.0153 \\
\hline$W e($ in $\%)$ & 3.988 & 3.87 & 2.4807 & 0.00 & 26.67 & 751 & 0.0643 \\
\hline Past (in \%) & 1.524 & 1.34 & 1.2019 & 0.00 & 8.00 & 751 & -0.0910 \\
\hline Interval & 32.882 & 16 & 67.8472 & 0.00 & 662.00 & 650 & -0.3532 \\
\hline$W C$ & 256.163 & 222 & 176.9025 & 1.00 & $1,293.00$ & 751 & -0.0272 \\
\hline
\end{tabular}

97 campaigns. All variables are defined in Table 1. Corr denotes the pairwise Bravais-Pearson Correlation Coefficients with $F$ IN 
Table 3 Summary statistics investment data set

\section{INVESTMENT DATA SET}

\begin{tabular}{|c|c|c|c|c|c|c|c|}
\hline Binary Variables & Yes & Mean & Median & SD & \# Obs. & & \\
\hline Update & 314 & 0.061 & 0 & 0.2387 & 5,176 & & \\
\hline Business & 94 & 0.018 & 0 & 0.1335 & 5,176 & & \\
\hline Business Model & 156 & 0.030 & 0 & 0.1709 & 5,176 & & \\
\hline Campaign & 83 & 0.016 & 0 & 0.1256 & 5,176 & & \\
\hline Certification & 106 & 0.020 & 0 & 0.1416 & 5,176 & & \\
\hline Cooperation & 82 & 0.015 & 0 & 0.1248 & 5,176 & & \\
\hline Emotional & 62 & 0.012 & 0 & 0.1088 & 5,176 & & \\
\hline New Funding & 23 & 0.004 & 0 & 0.0665 & 5,176 & & \\
\hline Product & 136 & 0.026 & 0 & 0.1599 & 5,167 & & \\
\hline Promotions & 146 & 0.028 & 0 & 0.1655 & 5,176 & & \\
\hline Team & 45 & 0.009 & 0 & 0.0928 & 5,176 & & \\
\hline Metric Variables & Mean & Median & SD & Min. & Max. & \# Obs. & Corr \\
\hline Alarm & 0.02 & 0 & 0.1349 & 0 & 1 & 5,176 & -0.0049 \\
\hline \# Investments & 47 & 30 & 72.1444 & 0 & 1160 & 5,176 & 0.0586 \\
\hline Amount & 497,352 & 141,500 & $1,254,637$ & 1,260 & $7,497,250$ & 5,176 & -0.0557 \\
\hline Funding Goal & 112,459 & 50,000 & 211,229 & 25,000 & $1,000,000$ & 5,176 & -0.0643 \\
\hline$V D A X$ & 18.20 & 17.63 & 3.2100 & 12.70 & 32.08 & 5,176 & -0.0120 \\
\hline Portal & 0.55 & 1 & 0.4977 & 0 & 1 & 5,176 & 0.0272 \\
\hline Post Funded & 0.86 & 1 & 0.3489 & 0 & 1 & 5,176 & 0.0059 \\
\hline Equity Share & 0.02 & 0.02 & 0.0246 & 0.0045 & 0.23 & 5,176 & 0.0040 \\
\hline$\%$ Invested & 4.51 & 2.99 & 4.1910 & 0.0075 & 20 & 5,176 & -0.0010 \\
\hline \% Invested 1 Day & 1.5876 & 0.7987 & 2.3098 & 0.0075 & 14.9975 & 71 & -0.1948 \\
\hline Update 1 Day & 0.2535 & 0 & 0.4381 & 0 & 1 & 71 & -0.3133 \\
\hline
\end{tabular}

71 campaigns. All variables are defined in Table 1. Corr denotes the pairwise Bravais-Pearson Correlation Coefficients with Update and Time, respectively

post updates soon after the campaign commencement to show that they are well prepared for the campaign and thus indicate a high campaign quality.

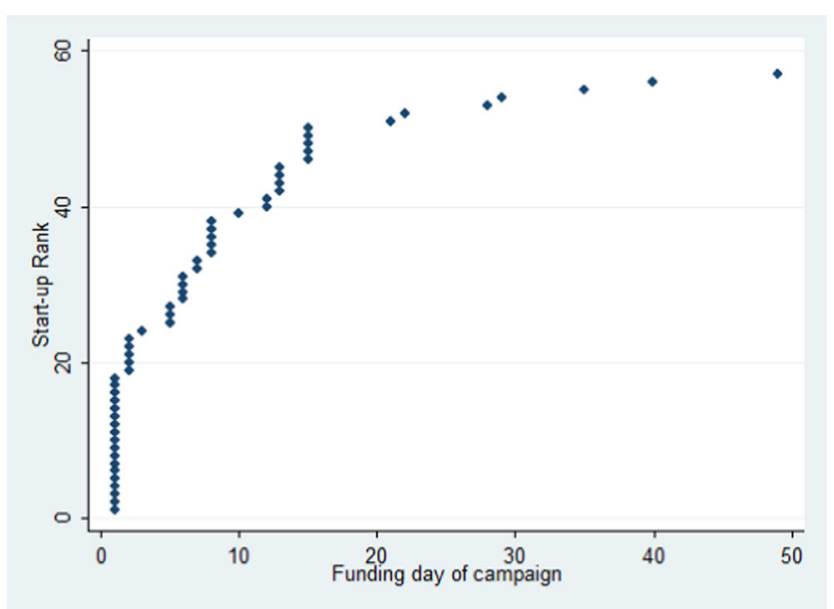

Fig. 1 Time to first Update

Number of days until the first update is published. Investment Data Set
The majority of the equity crowdfunding campaigns managed to reach their funding goal quickly, but, 6 campaigns were not able to achieve the funding goal before three quarters of the funding period had elapsed. Overall, 47 investments were made on an average campaign day. By comparison, an average of 7.56 investments were made each day in a particular campaign.

\section{Univariate Analysis: Changes in communication behavior after the funding period}

To investigate modifications in the communication behavior during and after the funding period, we apply a univariate analysis. As we observe several updates per campaign, we have to consider the correlation between updates within the same campaign. For the continuous dependent variables, we use a Feasible Generalized Least Squares (FGLS) estimation. According to Cameron and Miller (2015), a FGLS estimator can lead to efficiency gains compared with OLS when accounting for dependencies within groups. We perform a modified Hausman test and, in case the Hausman 
Table 4 Regression Results Funding Period,

FGLS-Estimation

\begin{tabular}{|c|c|c|c|c|c|c|}
\hline & \multicolumn{2}{|c|}{ Hypothesis 1} & \multicolumn{2}{|c|}{ Hypothesis 2} & \multicolumn{2}{|l|}{ Additional } \\
\hline & Positive & Negative & We & Past & Interval & $W C$ \\
\hline $\begin{array}{l}\text { FIN } \\
\text { Constant }\end{array}$ & $\begin{array}{l}0.0784 \\
(0.3662) \\
3.9339 * * * \\
(0.2440)\end{array}$ & $\begin{array}{l}-0.0635 \\
(0.0535) \\
0.3250 * * * \\
(0.0552)\end{array}$ & $\begin{array}{l}0.8012 * * * \\
(0.2519) \\
3.5056 * * * \\
(0.1516)\end{array}$ & $\begin{array}{l}-0.3879 * * \\
(0.1518) \\
1.7572 * * * \\
(0.0913)\end{array}$ & $\begin{array}{l}-55.8470 * * * \\
(8.7571) \\
75.8570 * * * \\
(9.7145)\end{array}$ & $\begin{array}{l}-5.7234 \\
(14.6006) \\
250.3666 * * * \\
(15.2357)\end{array}$ \\
\hline $\begin{array}{l}\text { \# Obs. } \\
R^{2}\end{array}$ & $\begin{array}{l}751 \\
0.0001\end{array}$ & $\begin{array}{l}751 \\
0.0002\end{array}$ & $\begin{array}{l}751 \\
0.0187\end{array}$ & $\begin{array}{l}751 \\
0.0163\end{array}$ & $\begin{array}{l}650 \\
0.1248\end{array}$ & $\begin{array}{l}751 \\
0.0007\end{array}$ \\
\hline
\end{tabular}

This table reports upon regression results using the Updates Data Set and random-effects model (dependent variables: Positive, Negative, Interval, WC) and fixed-effects model (dependent variables: We, Past). Heteroskedasticity-robust standard errors are shown in parentheses. For regression models with randomeffects the overall- $R^{2}$ and for those with fixed-effects the Within- $R^{2}$ are shown. $* *$ and $* * *$ denote significance at a $5 \%$ - and $1 \%$-level test leads us to dismiss the random effects estimator, we apply fixed effects. Otherwise we retain random effects. For binary dependent variables (i.e. the update categories), we use a probit regression with standard errors clustered at campaign level. To test whether there are differences between the funding period and the subsequent time, we use a dummy for the funding period $(F I N)$ as an explanatory variable. In case the coefficient of this dummy is significantly different from zero with a positive (negative) value, significantly more (less) updates of this category are posted within the funding period. Tables 4 and 5 present the results.

We find several significant changes in the communication behavior of start-ups over time. To begin with, the frequency of updates differs significantly between the funding period and the period thereafter. During the funding period on average 56 days less go by than after the funding period until a subsequent update is published. This result indicates that for many start-ups, obtaining funding is indeed the primary goal of an equity crowdfunding campaign. Yet since entrepreneurs continue to communicate with investors after the successful funding, non-monetary motivations play a role in equity crowdfunding as well.

The sentiment of the updates is not significantly different between the funding period and the period thereafter. The updates contain neither less positive nor more negative words once the funding has been completed. Hence we find no evidence to support our first hypothesis that start-ups use a positive tone in updates during the funding period in order to encourage investors. However, the results suggest that start-ups use different devices to the sentiment of the update to reach out to the crowd. We observe a significant positive relationship between the funding period and updates that use emotional language (Emotional). Furthermore, the updates
Table 5 Marginal effects funding period, probit-estimation

\begin{tabular}{|c|c|c|c|c|c|}
\hline & \multirow{2}{*}{$\begin{array}{l}\text { Hypothesis } 2 \\
\text { Emotional }\end{array}$} & \multicolumn{3}{|c|}{ Hypothesis 3} & \multirow[b]{2}{*}{ Promotions } \\
\hline & & Cooperation & New Funding & Business & \\
\hline FIN & $\begin{array}{l}0.0782 * * \\
(0.0342)\end{array}$ & $\begin{array}{l}0.0150 \\
(0.0421)\end{array}$ & $\begin{array}{l}0.0307 \\
(0.0233)\end{array}$ & $\begin{array}{l}0.1442 * * * \\
(0.0484)\end{array}$ & $\begin{array}{l}-0.1256^{* *} \\
(0.0520)\end{array}$ \\
\hline \# Obs. & 751 & 751 & 751 & 751 & 751 \\
\hline Pseudo- $R^{2}$ & 0.0124 & 0.0003 & 0.0069 & 0.0238 & 0.0113 \\
\hline
\end{tabular}

Additional

\begin{tabular}{llllll} 
& Team & Business Model & Certification & Product & Campaign \\
\hline FIN & -0.0130 & 0.0298 & $-0.1112^{* * *}$ & 0.0237 & $0.2105^{* * *}$ \\
& $(0.0295)$ & $(0.0442)$ & $(0.0565)$ & $(0.0480)$ & $(0.0341)$ \\
\# Obs. & 751 & 751 & 751 & 751 & 751 \\
Pseudo- $R^{2}$ & 0.0006 & 0.0006 & 0.0098 & 0.0004 & 0.0668 \\
\hline
\end{tabular}

This table reports upon average marginal effects using the Updates Data Set and probit regressions. Clusterand heteroskedasticity-robust standard errors are shown in parentheses. *, **, and *** denote significance at a $10 \%-, 5 \%-$, and $1 \%$-level 
during the funding period contain significantly more first person plural and less past tenses than updates subsequent to the funding period. The latter relationship may exist due to the fact that most start-ups run equity crowdfunding campaigns to obtain seed finance. Many of these start-ups started their businesses recently and may not have had past events to report upon in the equity crowdfunding campaign. Overall, the results support our second hypothesis, which is that updates during the funding period contain more linguistic devices evoking a feeling of group cohesion and improving group identity than updates posted after the end of the campaign.

We also investigate whether the usage of updates with a specific content differs between the funding period and the period thereafter. Since the latter period is, on average, longer than the funding period, overall more disclosable information should be available in the later period. However, two update categories, namely Business and Campaign have a significant positive relationship with $F I N$. The fact that significantly more updates containing information about the development of the businesses are published during the funding period represents evidence in favor of our third hypothesis, being that entrepreneurs strategically use updates about new developments of the start-up. The positive relationship between $F I N$ and Campaign is not surprising, either. This effect is driven by the fact that startups post more information about the campaign progress, such as the achieved funding amount or the number of backers on a particular day, during the funding period than after the successful funding. The two other categories that we hypothesize are posted more often during the funding period, NewFunding and Cooperation, are not significantly associated with $F I N$ in our analysis. This is possibly due to the fact that start-ups indeed require relevant hard information to be able to publish updates in these categories. It is less difficult, for example, to publish easily obtainable sales figures (Business) in the funding period than information about a new strategic cooperation that may simply not exist.

Overall, we find some evidence in favor for our third hypothesis. One out of three categories, namely Business, shows the expected correlation with the funding period. Therefore, the data weakly supports our third hypothesis. Indeed the different results for Business, NewFunding and Cooperation indicate that start-ups strategically change the content of updates during the funding period and thereafter.

We also find that start-ups post significantly fewer updates about external certification and promotions during the funding period than thereafter. In many cases, the start-ups do not have a fully developed product at the time of the equity crowdfunding campaign. Therefore, many start-ups are not able to post updates about external certification during the funding period. Furthermore, the funding period is shorter than the following period. Due to this extended time period, the probability of a disclosable hard information rises.

Block et al. (2018) point out that the length of the update text is not significantly associated with investments. In line with this result, we do not find any evidence to suggest that updates during the funding period contain more words than subsequent updates.

\section{Multivariate analysis: Communication dynamics during the funding period}

Why do entrepreneurs post an update on a specific campaign day? To answer this question, we estimate several statistical models. Our dependent variables are binary and equal to one if an update or an update of a specific category is posted on a particular campaign day and zero otherwise. We begin with panel models and apply a Hausman test. We have to dismiss the random-effects model as it is inconsistent for our data. However, the fixed-effects logit model only uses variation within the campaign and therefore implies heavy losses of observations depending on the update category. Furthermore, coefficients for timeinvariant regressors cannot be estimated. Thus we use a pooled probit regression as a main model and include the fixed-effects model as a robustness check. Table 6 presents the results for the pooled probit with 'posting of an update' and 'posting of an update with a specific content' as dependent variables, respectively.

In a first step, we examine whether start-ups are more likely to post updates when they have not reached the funding goal and the remaining funding period is short. We find that effects differ for the update categories. While we observe a significant positive relationship between the Alarm dummy and emotional updates as well as those updates which disclose information about the business and campaign development, all other categories are insignificant. We cannot estimate average marginal effects for updates about new funding sources and the entrepreneurial team as these updates are never posted when the Alarm dummy equals one. The probability of an update increases for the significant categories, Campaign, Business, and Emotional, by between $1.7 \%$ and $2.8 \%$ when the Alarm dummy equals one. On the one hand, the significant positive effect of the Alarm dummy on emotional updates and those disclosing information on the business development suggest strategic communication behavior of start-ups. Since the availability of disclosable information should not change over the course of the campaign, a significant change in the communication behavior indicates a strategic posting of updates. On the other hand, New Funding and Cooperation, the two other 


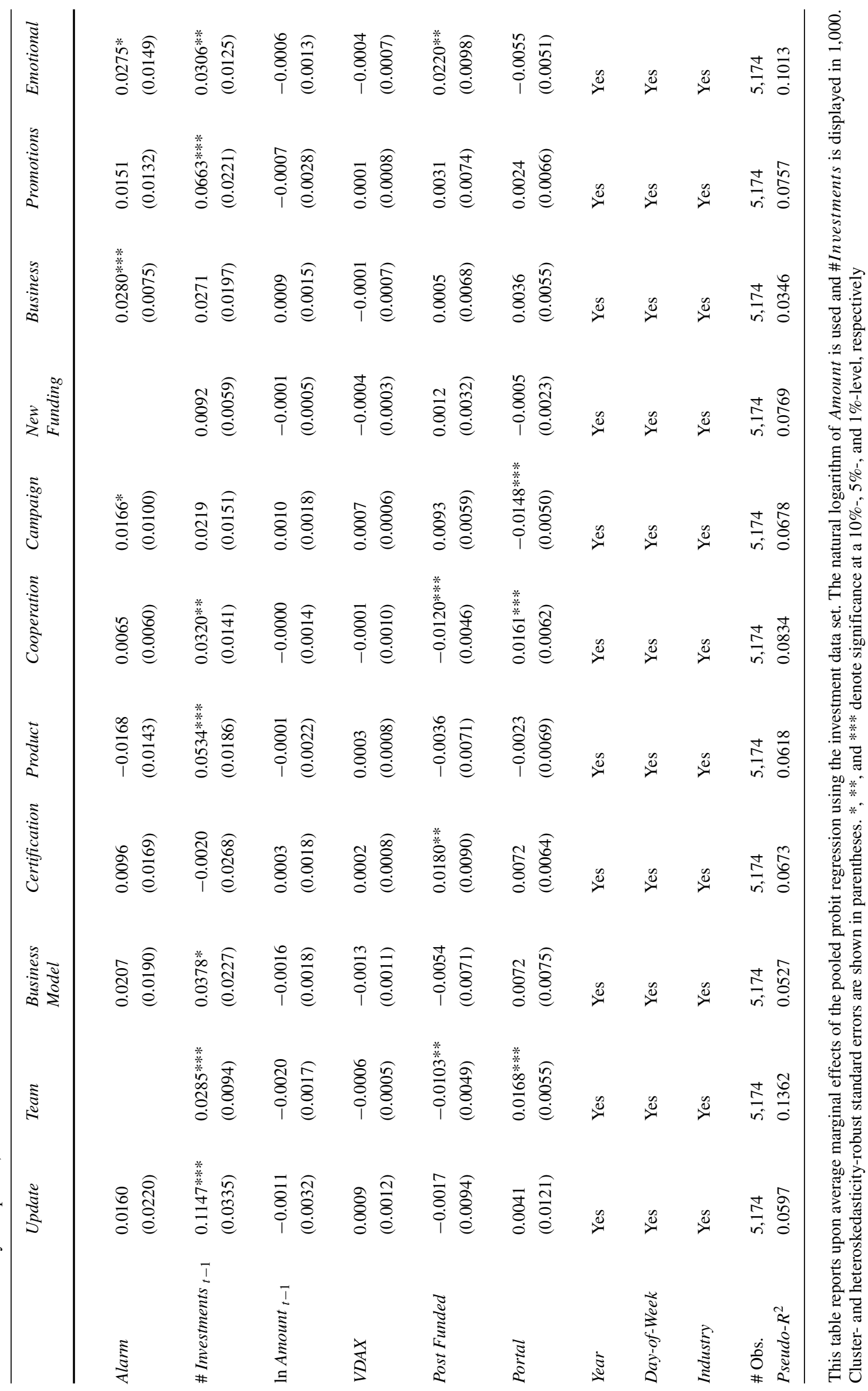


categories that increase investments according to Block et al. (2018) are not significant in our data. However, this may again be due to the fact that start-ups need disclosable information in order to publish updates within these categories. Overall, we only find weak evidence to support our forth hypothesis which is that start-ups are more likely to post an update when the funding goal is not reached and the remaining funding period is short.

In a second step, we focus on the competitive environment of equity crowdfunding campaigns. We observe a significant positive relationship between the total number of investments in equity crowdfunding campaigns on the overall market during the previous day and the probability of an update in the focal campaign. An increase in the total number of investments by 1,000 is associated with an $11.47 \%$ increase in the probability of an update. In times of a highly competitive environment, start-ups therefore attempt to draw attention to their campaigns by posting updates, thereby attracting backers. This relationship also holds for most of the update categories. Updates of the categories Team, Business Model, Product, Cooperation, Promotions and Emotional are significantly positively associated with the total number of investments on the market. Overall, the results therefore support our fifth hypothesis which is that the likelihood of an update increases along with market competition.

Our second proxy for the campaign success, the amount invested prior to the previous day, is not significantly related to the probability of an update. With respect to the other control variables, we observe a significant relationship between the probability of an update and the ability to reach the funding goal (PostFunded) as well as the $V D A X$ for some categories. The portal on which the equity crowdfunding campaign is run also plays a role for some of the update categories. The sign, however, differs between the categories under consideration. While significantly more updates about the entrepreneurial team and collaborations of the start-up are posted on Companisto, significantly less updates are disclosed concerning the campaign development.

To consider endogeneity on a campaign level, we perform a fixed-effects logit regression. The results are presented in Table 7. They show a significant positive relationship between the probability of an update of the Business category and the Alarm dummy. Furthermore, we can confirm the previous results regarding the significant positive impact of competing investments on updates in general and on those that disclose information about Team, Product, Cooperation, Business, Promotions, and Emotional in particular. In this way, we show that our main results are not driven by unobserved time-invariant variables.
As an alternative model, we apply survival analysis and perform a Cox proportional hazard model with the number of days before the update is posted as a dependent variable. By using this model we are able to analyze the duration, i.e. the time that elapses before an update (or an update with a particular content) is published considering various covariates. The Cox model applies a semi-parametric method to estimate the impact of the covariates on the hazard rate. In this context, the hazard rate represents the chance of an update being published on the next day when taking into consideration the time period that has already passed. As we have so-called multiple-failure data, i.e. each campaign can exhibit more than one update, we cluster the standard errors at campaign level. The results are shown in Table 8. In this analysis we report on hazard ratios, which can be interpreted as semi-elasticity or multiplicative effect.

The results are similar to those of the pooled-probit model. We can confirm the positive relationship between updates which disclose information about the business development as well as emotional updates and the Alarm dummy. Furthermore, we find a positive relationship between the total number of investments and the probability of an update being posted for most of the update categories. We test the proportionality assumption of the Cox model for all explanatory variables. In case the assumption is violated, we include an interaction term of the explanatory variable with time $(t)$. The interaction term \#Investments.t indicates that the effect of competition of contemporary equity crowdfunding campaigns is not constant but decreases over time both for updates in general and for those that disclose information about the entrepreneurial team, the business model, the product, the business development, as well as emotional updates.

Using the Cox proportional hazard model, our second proxy for the success of the campaign, Amount, is significantly negatively associated with the probability of an update. Start-ups with a lower amount of funding are more likely to post an update. This result provides further evidence of the strategic communication behavior of startups. Again, the interaction term between Amount and the time period suggests a decreasing effect of Amount on the probability of an update over time.

\section{Further analysis}

Colombo et al. (2015), Kuppuswamy and Bayus (2017), and Vulkan et al. (2016) highlight the fact that collective attention at the beginning of the campaign is crucial: crowdfunding campaigns that attract investors in the early phase of the funding period are significantly more successful. Our descriptive analysis of the data has also shown that start-ups tend to post updates soon after the 


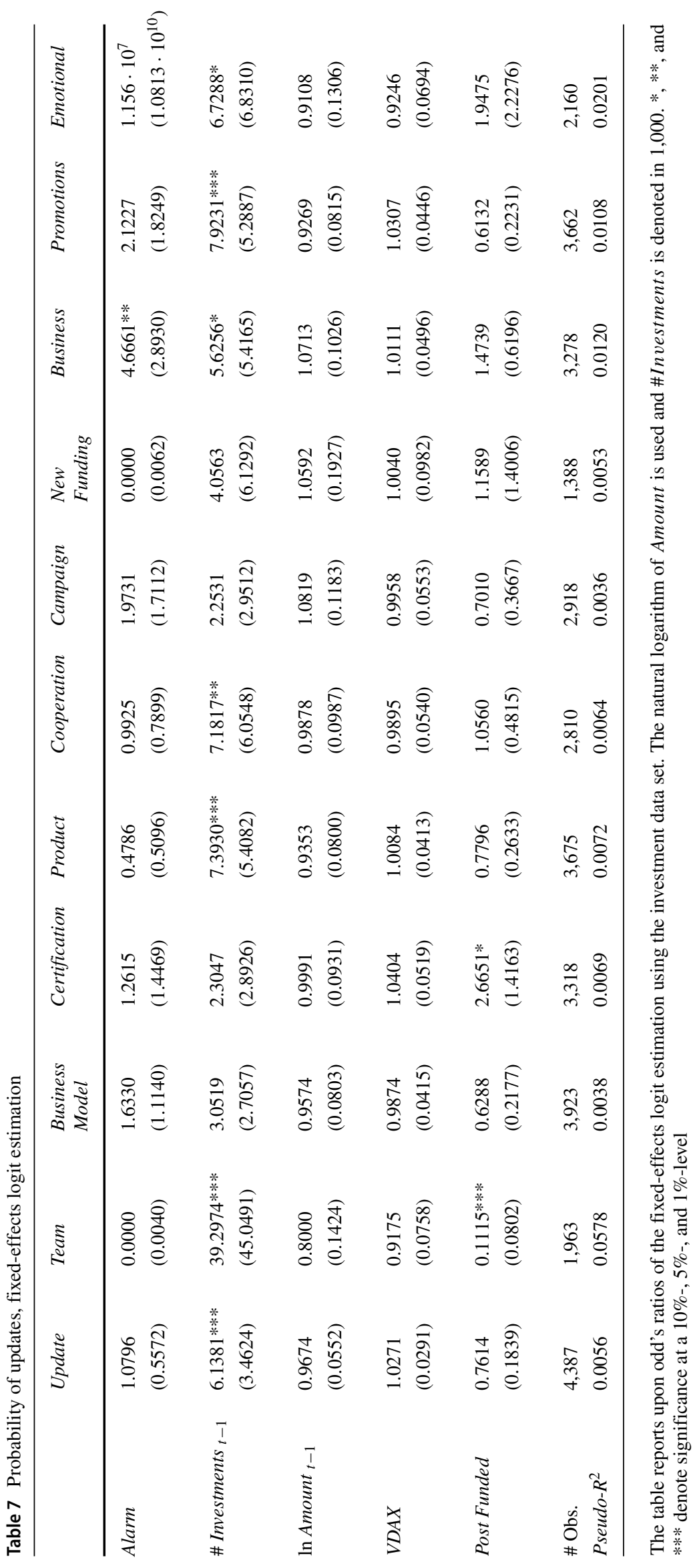




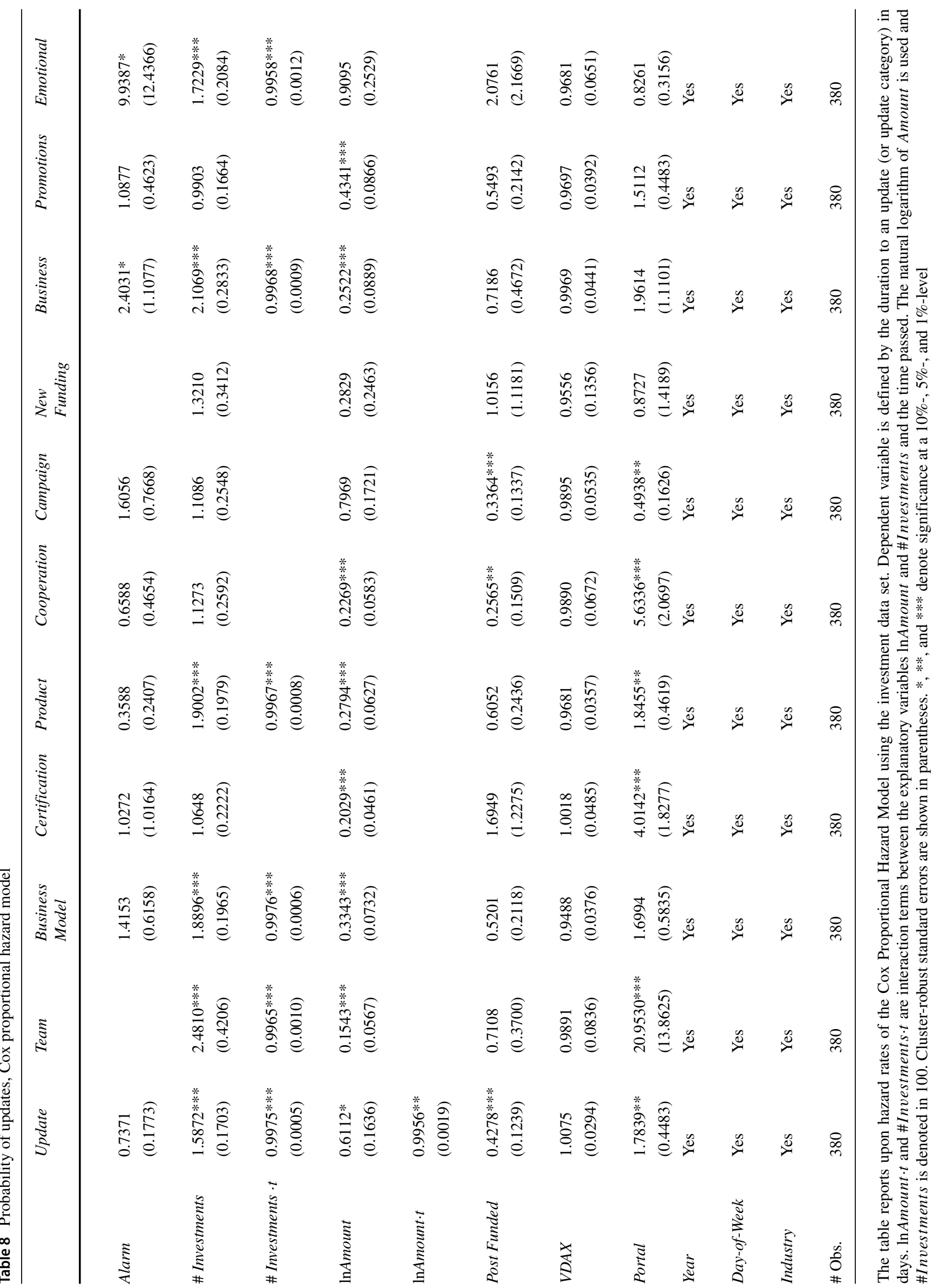


campaign starts. In order to analyze the communication behavior of the first stage of the funding period in more detail, we consider the duration before the first update is posted. As a main model, we use a Cox proportional hazard model. An advantage of the survival analysis in this context is that we deal with right censoring. We do not only consider the campaigns with a first update but also those campaigns that did not post an update during the funding period. The results are presented in column 1 and 3 of Table 9. Furthermore, we apply a negative binomial model to investigate the number of days before the first update is published. Columns 2 and 4 in Table 9 show the results for the negative binomial estimations.

The updates posted on the very first day of a campaign are not usually linked to the progress of the campaign. Hence we use two different subsamples: one in which we omit updates posted on the first day (model 1 and 2) and one in which we include these updates (model 3 and 4).

In the first two models we do not only consider explanatory variables that are determined before the commencement of the campaign but also two variables indicating the success of the campaign and the competitive environment on the first day of the campaign. However, the results suggest that neither the number of competing investments on the first day nor the portion of the funding goal reached on the first day are significantly associated with the time until the update is posted. This indicates that the competitive environment and the success of a campaign are less important for the posting of the first update. In models 1 and 2 we also include a dummy

Table 9 Time to first update

\begin{tabular}{|c|c|c|c|c|}
\hline & Model 1 & Model 2 & Model 3 & Model 4 \\
\hline \# Investments $_{t=1}$ & $\begin{array}{l}1.0019 \\
(0.0031)\end{array}$ & $\begin{array}{l}-0.0270 \\
(0.0223)\end{array}$ & & \\
\hline$\%$ Invested $_{t=1}$ & $\begin{array}{l}0.8957 \\
(0.1824)\end{array}$ & $\begin{array}{l}-0.6231 \\
(1.4694)\end{array}$ & & \\
\hline Update 1 Day & $\begin{array}{l}2.3052 * \\
(1.0285)\end{array}$ & $\begin{array}{l}-1.2878 \\
(2.9089)\end{array}$ & & \\
\hline Portal & $\begin{array}{l}1.1230 \\
(0.5329)\end{array}$ & $\begin{array}{l}-4.1340 \\
(3.1047)\end{array}$ & $\begin{array}{l}2.2760 * * \\
(0.9069)\end{array}$ & $\begin{array}{l}-10.2619 * * * \\
(3.6149)\end{array}$ \\
\hline Equity Share & $\begin{array}{l}224.4835 \\
(1335.9686)\end{array}$ & $\begin{array}{l}-24.4252 \\
(47.3784)\end{array}$ & $\begin{array}{l}886.9319 \\
(5361.6060)\end{array}$ & $\begin{array}{l}-62.9241 \\
(56.9074)\end{array}$ \\
\hline Funding Goal & $\begin{array}{l}224.4835 \\
(1335.9686)\end{array}$ & $\begin{array}{l}0.1046 \\
(0.3569)\end{array}$ & $\begin{array}{l}0.9704 \\
(0.0436)\end{array}$ & $\begin{array}{l}0.4514 \\
(0.4271)\end{array}$ \\
\hline Industry & Yes & Yes & Yes & Yes \\
\hline Year & Yes & Yes & Yes & Yes \\
\hline \# Obs. & 71 & 57 & 71 & 57 \\
\hline Pseudo- $R^{2}$ & 0.0850 & 0.072 & 0.0832 & 0.0786 \\
\hline
\end{tabular}

This table reports upon hazard rates of a Cox Proportional Hazard Model and marginal effects of a negative binomial regression using the investment data set. The dependent variable constitutes the time elapsed before the first update is published (Time). Model 1 and 2 do not consider updates posted on the very first day of campaign, models 3 and 4 include updates posted on the first day. In models 1 and 3 we estimate a Cox Proportional Hazard Model in models 3 and 4 a negative binomial regression. FundingGoal is denoted in 10,000 EUR. *, **, and $* * *$ denote significance at a $10 \%-, 5 \%-$, and $1 \%$-level 
variable indicating whether or not an update has been posted on the first campaign day. Interestingly, by using the Cox proportional hazard model we find that start-ups which post an update on the first day of a campaign make subsequent updates significantly quicker. Hence start-ups which start to communicate with investors early on appear to communicate more frequently later as well.

When also considering updates posted on the first campaign day (model 3 and 4), we find that the portal is significantly associated with the time before the first update is posted. In particular, for campaigns run on the platform Companisto, the time before the first update is published is significantly shorter. This finding can be considered as evidence of the fact that portals are critical concerning the promotion of entrepreneurs who run successful equity crowdfunding campaigns.

\section{Conclusion}

Entrepreneurship literature has extensively analyzed the interactions between venture capitalists or angel investors and entrepreneurs as well as the strategic behavior of each party (for example Sahlman 1990; Schwienbacher 2007; Mohamed and Schwienbacher 2016). However, up to now, little has been known about the strategic behavior of entrepreneurs in crowdfunding. In this paper, we investigate the communication behavior of start-ups during and after an equity crowdfunding campaign. Such an investigation is important because, in contrast to venture capitalists, crowd investors neither obtain information from an insider from the board of directors nor do they receive news through contractual obligations such as specific covenants. Furthermore, in crowdfunding, the form and the content of voluntary disclosure is not specifically regulated through ad hoc disclosure requirements. Platforms often do not verify the disclosed information and thus entrepreneurs can strategically publish information through updates.

We use a data set of German equity crowdfunding campaigns in order to examine five hypothesis related to our research questions. The empirical evidence from our first hypothesis shows that the probability of an update increases along with stronger competition from parallel equity crowdfunding campaigns. There is only weak evidence in favor of a higher probability of updates when the campaign comes to an end and the reaching the funding goal becomes increasingly difficult. While the latter can be regarded as a sign of regular communication, the first finding indicates that start-ups indeed place their updates in such a way as to attract more attention. Regarding the question to what extent and how the communication behavior changes after the funding has been granted, we consider three hypotheses. While the hypothesis being that the tone of the updates is more positive during funding periods than thereafter, cannot be confirmed, we find evidence that during the funding period start-ups use a language that evokes warm-glow effects among potential investors and a feeling of group cohesion. Furthermore, we find some evidence to support the hypothesis that start-ups strategically post updates about the business development during the funding period. Moreover, they clearly post fewer updates after the funding has been ensured. All in all, this evidence indicates that during the funding period, the start-ups strategically place their updates with respect to frequency, content and the purpose to evoke emotions.

From these findings, we deduce the following implications for actors in the field. Given that equity crowdfunding often falls outside traditional securities regulation and, in particular, outside the securities prospectus regime as well as the market abuse regulation, securities regulators and platform providers should be wary about the content that start-ups post during an equity crowdfunding campaign. If equity crowdfunding further increases in importance, rules for investor communication may become necessary. For investors who primarily seek to maximize their return and who are not attracted by non-monetary motives, the strategic communication behavior may lead to sub-optimal investment decisions. This could be due possibly to blurred informational content of some updates which may be targeted at receiving funds and which do not accurately reveal real information. Whether a specific type of communication behavior of start-ups indeed leads to lower returns for investors should be investigated once the respective data becomes available. This is particularly relevant, given that little is know about the truthfulness of the information communicated by the start-ups. If start-ups systematically and strategically post fraudulent updates with the aim to increase investments, regulators have to consider enhancing investor protection in the context of equity crowdfunding. Our research suggests that companies that seek funding through an equity crowdfunding campaign should not rely too heavily on their strategic behavior as it can be revealed through systematic investigation.

Our paper also has clear limitations. With 97 campaigns (updates data set) and 71 campaigns (investment data set), our samples barely allow us to conduct extensive subsample analyses for different industries or founder teams. For example, larger founder teams may have better capacities and could be more creative in strategically posting updates. At the same time, they might also provide better checks and balances when it comes to the content of information disclosure. We use solely data from German platforms. Yet major international equity crowdfunding platforms such as Crowdcube and Seedrs have similar business models and also allow for updates both during and after the funding period. Therefore, the findings from our German data set can in 
principle be applied to many equity crowdfunding platforms worldwide, at least in the sense of an anticipated behavior.

Future research may focus on the learning process of entrepreneurs. Entrepreneurs with experience from multiple crowdfunding campaigns could apply a more sophisticated communication strategy than first-timers. Furthermore, the effects of mandatory disclosure in equity crowdfunding could also be of interest. In the context of venture capital, Cumming and Knill (2012) find evidence for a positive effect of strict disclosure requirements on both the supply and the performance of venture capital.

Funding Information Open access funding provided by Max Planck Society. The article evolved as part of the research project "Crowdinvesting in Germany, England and the USA: Regulatory Perspectives and Welfare Implications of a New Financing Scheme", which was supported by the German Research Foundation (Deutsche Forschungsgemeinschaft) under the grant number H05296/1-1.

Open Access This article is distributed under the terms of the Creative Commons Attribution 4.0 International License (http:// creativecommons.org/licenses/by/4.0/), which permits unrestricted use, distribution, and reproduction in any medium, provided you give appropriate credit to the original author(s) and the source, provide a link to the Creative Commons license, and indicate if changes were made.

\section{References}

Ahlers, G.K., Cumming, D., Günther, C., Schweizer, D. (2015). Signaling in equity crowdfunding. Entrepreneurship Theory and Practice, 39(4), 955-980.

Allison, T.H., McKenny, A.F., Short, J.C. (2013). The effect of entrepreneurial rhetoric on microlending investment: an examination of the warm-glow effect. Journal of Business Venturing, 28, 690-707.

Andreoni, J. (1990). Impure altruism and donations to public goods: a theory of warm-glow giving. Economic Journal, 100(401), 464-477.

Baum, J.R., \& Locke, E.A. (2004). The relationship of entrepreneurial traits, skill, and motivation to subsequent venture growth. Journal of Applied Psychology Copyright 2004 by the American Psychological Association, 89(4), 587-598.

Bernstein, S., Korteweg, A., Laws, K. (2017). Attracting early-stage investors: Evidence from a randomized field experiment. The Journal of Finance, 72(2), 509-538.

Block, J., Hornuf, L., Moritz, A. (2018). Which updates during an equity crowdfunding campaign increase crowd participation? Small Business Economics, 50, 3-27.

Cameron, A.C., \& Miller, D.L. (2015). A practitioners guide to clusterrobust inference. Journal of Human Resources, 20(2), 317-372.

Cardon, M.S., Wincent, J., Singh, J., Drnovsek, M. (2009). The nature and experience of entrepreneurial passion. Academy of Management Review, 34(3), 511-532.

Chen, X.-P., Yao, X., Kotha, S. (2009). Entrepreneur passion and preparedness in business plan presentations: a persuasion analysis of venture capitalists' funding decisions. Academy of Management Journal, 52(1), 199-214.

Cohen, J. (1960). A coefficient of agreement for nominal scales. Educational and Psychological Measurement, 20(1), 37-46.
Colombo, M.G., Franzoni, C., Rossi-Lamastra, C. (2015). Internal social capital and the attraction of early contributions in crowdfunding. Entrepreneurship Theory and Practice, 39(1), 75-100.

Cumming, D., \& Knill, A. (2012). Disclosure, venture capital and entrepreneurial spawning. Journal of International Business Studies, 43, 563-590.

Darrough, M.N., \& Stoughton, N.M. (1990). Financial disclosure policy in an entry game. Journal of Accounting and Economics, 12(1-3), 219-243.

Davis, A.K., Piger, J.M., Sedor, L.M. (2012). Beyond the numbers: Measuring the information content of earnings press release language. Contemporary Accounting Research, 29(3), 845-868.

Diamond, D.W., \& Verrecchia, R.E. (1991). Disclosure, liquidity, and the cost of capital. The Journal of Finance, 46(4), 1325-1359.

Doshi, A.R. (2016). The impact of high-performance outliers on twosided platforms: Evidence from crowdfunding. SSRN Working Paper Nr. 2422111.

Fleiss, J.L., Levin, B., Paik, M.C. (2003). Statistical methods for rates and proportions; 3 ed. Wiley Series In Probability and Statistics. Hoboken: Wiley.

Gerber, E., \& Hui, J. (2013). Crowdfunding: Motivations and deterrents for participation. ACM Transactions on ComputingHuman Interaction, 20(6), 1-32.

Hamari, J., Sjöklint, M., Ukkonen, A. (2016). The sharing economy: Why people participate in collaborative consumption. Journal of the Association for Information Science and Technology, 67(9), 2047-2059.

Healy, P.M., \& Palepu, K.G. (2001). Information asymmetry, corporate disclosure, and the capital markets: a review of the empirical disclosure literature. Journal of Accounting and Economics, 31(1-3), 405-440.

Henry, E. (2008). Are investors influenced by how earnings press releases are written?. International Journal of Business Communication, 45(4), 363-407.

Hornuf, L., \& Schmitt, M. (2016). Success and failure in equity crowdfunding. CESifo DICE Report, 14(2), 16-22.

Hornuf, L., \& Schwienbacher, A. (2017). Market mechanisms and funding dynamics in equity crowdfunding. Journal of Corporate Finance (Forthcoming).

Hornuf, L., \& Neuenkirch, M. (2017). Pricing shares in equity crowdfunding. Small Business Economics, 48(4), 795-811.

Hornuf, L., Schmitt, M., Stenzhorn, E. (2018). Equity crowdfunding in Germany and the uk: Follow-up funding and firm survival. Max Planck Institute for Innovation and Competition Research Paper No. 17-09.

Kickstarter (2012). Blockbuster effects. https://www.kickstarter.com/ blog/blockbuster-effects.

Klöhn, L., \& Hornuf, L. (2012). Crowdinvesting in Deutschland Markt, Rechtslage und Regulierungsperspektiven. Z. Bankrecht Bankwirtschaft, 24(4), 237-266.

Kuppuswamy, V., \& Bayus, B.L. (2017). Does my contribution to your crowdfunding project matter?. Journal of Business Venturing, 32(1), 72-89.

Landis, J.R., \& Koch, G.G. (1977). The measurement of observer agreement for categorical data. Biometrics, 33(1), 159-174.

Li, F. (2010). The information content of forward-looking statements in corporate filings - a naive Bayesian machine learning approach. Journal of Accounting Research, 48(5), 10491102.

Merton, R.C. (1987). A simple model of capital market equilibrium with incomplete information. The Journal of Finance, 42(3), 483-510.

Mohamed, A., \& Schwienbacher, A. (2016). Voluntary disclosure of corporate venture capital investments. Journal of Banking \& Finance, 68, 69-83. 
Mollick, E. (2014). The dynamics of crowdfunding: an exploratory study. Journal of Business Venturing, 29(1), 1-16.

Pennebaker, J.W., Francis, M.E., Booth, R.J. (2001). Linguistic Inquiry and Word Count - LIWC 2001. Erlbaum.

Reis, H., \& Judd, C. (2014). Handbook of Research Methods in Social and Personality Psychology. Cambridge: Cambridge University Press.

Sahlman, W.A. (1990). The structure and governance of venturecapital organizations. Journal of Financial Economics, 27(2), 473-521.

Schwienbacher, A. (2007). A theoretical analysis of optimal financing strategies for different types of capital-constrained entrepreneurs. Journal of Business Venturing, 22(6), 753-781.

Sexton, J.B., \& Helmreich, R.L. (2000). Analyzing cockpit communications: The links between language, performance, error, and workload. Journal of Human Performance in Extreme Environments, 5(1), 63-68.

Signori, A., \& Vismara, S. (2018). Returns on investments in equity crowdfunding. Journal of Corporate Finance (Forthcoming).

Spence, M. (2002). Signaling in retrospect and the informational structure of markets. American Economic Review, 92(3), 434-549.
Tausczik, Y.R., \& Pennebaker, J.W. (2010). The psychological meaning of words: Liwc and computerized text analysis methods. Journal of Language and Social Psychology, 29(1), 2454.

Vismara, S. (2016). Information cascades among investors in equity crowdfunding. Entrepreneurship Theory and Practice (Forthcoming).

Vulkan, N., Ȧstebro, T., Sierra, M.F. (2016). Equity crowdfunding: a new phenomena. Journal of Business Venturing Insights, 5, 37-49.

Wolf, M., Horn, A.B., Mehl, M.R., Haug, S., Pennebaker, J.W., Kordy, H. (2008). Computergestützte quantitative Textanalyse Äquivalenz und Robustheit der deutschen Version des Linguistic Inquiry and Word Count. Diagnostica, 54, 85-98.

Xu, A., Yang, X., Rao, H., Fu, W.-T., Huang, S.-W., Bailey, B.P. (2014). Show me the money! An analysis of project updates during crowdfunding campaigns. In Proceedings of the 32nd Annual ACM Conference for Human Factors in Computing Systems (pp. 591-600): ACM.

Zheng, T. (2000). Characteristics of Australian political language rhetoric: Tactics of gaining public support and shirking responsibility. Journal of Intercultural Communication, November, 4. 